\title{
Elastic bottom propagation mechanisms investigated by parabolic equation methods
}

\author{
Scott D. Frank \\ Marist College \\ Department of Mathematics \\ Poughkeepsie, NY 12601 \\ phone: (845) 575-3977 fax: (845) 575-3605 email: scott.frank@ marist.edu
}

Award Number: N00014-11-1-0268

\section{LONG-TERM GOALS}

Develop elastic parabolic equation (PE) method capabilities in order to study elastic propagation mechanisms and their effects on underwater acoustic environments in the form of scattering at an elastic interface, oceanic $T$-waves, and Scholte waves.

\section{OBJECTIVES}

To implement explosive and earthquake type seismic sources in current elastic parabolic equation methods for underwater acoustic environments. These will be used to investigate propagation mechanisms that depend on ocean bottom elastic properties and result in acoustic propagation in the ocean. Two examples of such propagation are oceanic $T$-waves, which are acoustic waves that result from earthquake or buried explosive sources, and Rayleigh-type waves along the ocean floor, whose existence requires horizontal and vertical displacements present in elastic sediments. The generation, propagation, and potential contribution of these waves to the otherwise quiet acoustic field of the deep ocean all require study, in particular as potential sources of unexplained deep shadow zone arrivals that have been experimentally observed below the ray-theoretic turning point.[1,2]

\section{APPROACH}

In a cylindrically symmetric environment, where $r$ is the distance from the source and $z$ is depth, recent parabolic equation methods for acoustic propagation in elastic sediments are based on the $\left(u_{r}, w\right)$ formulation of elasticity, where $u_{r}$ is the horizontal derivative of the horizontal displacement and $w$ is the vertical displacement.[3] The outgoing portion of the separated Helmholtz operator leads to the parabolic equation for a range-independent environment,

$$
\frac{\partial}{\partial r}\left(\begin{array}{c}
u_{r} \\
w
\end{array}\right)=i\left(L^{-1} M\right)^{1 / 2}\left(\begin{array}{c}
u_{r} \\
w
\end{array}\right), \quad u_{r}=\frac{\partial u}{\partial r},
$$

where $L$ and $M$ are matrices containing depth-dependent operators that incorporate compressional wave speed, $c_{p}$, shear wave speed, $c_{s}$, and density $\rho$ via the Lamé parameters of the elastic medium, $\lambda$ and $\mu$. 


\section{Report Documentation Page}

Form Approved

OMB No. 0704-0188

Public reporting burden for the collection of information is estimated to average 1 hour per response, including the time for reviewing instructions, searching existing data sources, gathering and maintaining the data needed, and completing and reviewing the collection of information. Send comments regarding this burden estimate or any other aspect of this collection of information,

including suggestions for reducing this burden, to Washington Headquarters Services, Directorate for Information Operations and Reports, 1215 Jefferson Davis Highway, Suite 1204, Arlington

VA 22202-4302. Respondents should be aware that notwithstanding any other provision of law, no person shall be subject to a penalty for failing to comply with a collection of information if it

does not display a currently valid OMB control number.

1. REPORT DATE

30 SEP 2014

4. TITLE AND SUBTITLE

Elastic Bottom Propagation Mechanisms Investigated by Parabolic Equation Methods

6. $\operatorname{AUTHOR}(\mathrm{S})$

7. PERFORMING ORGANIZATION NAME(S) AND ADDRESS(ES)

Marist College,Department of Mathematics,Poughkeepsie,NY,12601

9. SPONSORING/MONITORING AGENCY NAME(S) AND ADDRESS(ES)

12. DISTRIBUTION/AVAILABILITY STATEMENT

Approved for public release; distribution unlimited

13. SUPPLEMENTARY NOTES

14. ABSTRACT

15. SUBJECT TERMS

16. SECURITY CLASSIFICATION OF:

a. REPORT

unclassified b. ABSTRACT

unclassified c. THIS PAGE

unclassified
17. LIMITATION OF ABSTRACT

Same as Report (SAR)
3. DATES COVERED

00-00-2014 to 00-00-2014

5a. CONTRACT NUMBER

5b. GRANT NUMBER

5c. PROGRAM ELEMENT NUMBER

5d. PROJECT NUMBER

5e. TASK NUMBER

5f. WORK UNIT NUMBER

8. PERFORMING ORGANIZATION REPORT NUMBER

10. SPONSOR/MONITOR'S ACRONYM(S)

11. SPONSOR/MONITOR'S REPORT NUMBER(S) 
Range dependence is included by modeling sloping boundaries with a stair-step approximation and applying appropriate matching conditions at each vertical interface. This approach is combined with rotated variable methods [4] and an elastic single-scattering approximation[5] to obtain computationally stable solutions with improved accuracy in complex multi-layered range-dependent underwater acoustic environments.[6] Parabolic equation self-starters for sources in a fluid[7] or in an elastic material[3] have recently been tested for accuracy in underwater acoustic environments.[8] These are used for analysis of the effects of elastic parameters and underwater bathymetry on acoustic and seismoacoustic propagation.

Wavenumber content of range independent portions of an elastic PE solution $f(r)$ is calculated using the Hankel transform

$$
F(k, z)=\int_{r_{0}}^{R} f(r, z) J_{0}(k r) r d r
$$

where $r_{0}$ and $R$ mark the beginning and end of a range-independent portion of the environment, and $J_{0}(k r)$ represents the Bessel function of the first kind of order 0 . These results are used to resolve the nature of propagating acoustic modes and potential interface wave modes.

Downslope conversion, which occurs when a sloping ocean bottom causes the resulting transmission angle of incident elastic waves to focus acoustic waves into the SOFAR channel, is one of two primary mechanisms of oceanic $T$-wave generation.[9]. The second mechanism generates so-called abyssal $T$-waves from areas of the the deep ocean where there is no significant sloping bottom. It is believed that ocean bottom roughness scatters the elastic waves up into the water column and subsequently into the SOFAR channel.[10] Characteristics of underwater acoustic fields in the presence of Normally distributed ocean bottom roughness are determined by analysis of transmission loss results and wavenumber spectra resulting from multiple realizations.[11]

Scholte interface waves are excited by seismic sources and have been observed by seismometers at the ocean bottom. $[12,13]$ Energy from interface waves has also been detected by hydrophones near the seafloor[13] well below the SOFAR channel, suggesting these waves could influence deep-shadow zone arrivals observed during NPAL.[1, 2] Elastic wave theory predicts the Scholte wave speed to be approximately $0.8 c_{s}$. Thus, a peak in the wavenumber spectra calculated from elastic PE solutions near this speed indicates interface waves have been excited.

\section{WORK COMPLETED}

- The capability of PE solutions to generate abyssal oceanic $T$-waves from seismic sources has been verified by comparing transmission loss results for a flat seafloor to those from multiple Normally distributed rough bottom realizations.[14] These results have been utilized to describe effects of rough bottom ocean depth on $T$ wave generation and propagation by examining depth-averaged acoustic transmission results from elastic PE solutions.[11]

- Generation and SOFAR channel propagation of oceanic $T$ waves from seismic sources in the presence of intervening seamounts or coral reef barriers is established using elastic PE solutions.[11]

- Hankel transforms characterize how the range of large ocean bottom topography affects the presence and amplitude of Scholte wave arrivals at receiver distances of $100 \mathrm{~km} .[14]$ 
- Wavenumber spectra from a one layered elastic bottom environment with an intervening seamount demonstrate effects of elastic parameters on relationship between water column acoustic energy and ocean bottom elastic energy, including interface wave propagation.[15, 11$]$

- Elastic PE solutions with seismic sources[8] determine the connection between slope angle and amplitude of propagating oceanic $T$-waves.[11]

- Elastic PE solutions for long range SOFAR channel propagation of abyssal $T$-waves in a layered continental shelf environment exhibit Scholte interface waves and illustrate that these solutions provide on-shore seismic receptions.[11]

\section{RESULTS}

The generation of abyssal oceanic $T$-waves by small-scale range dependence was established by demonstrating acoustic transmission loss averaged over several realizations of Normally distributed bottom roughness is significantly lower than acoustic transmission loss for perfectly flat ocean bottoms. The left panel of Figure 1 shows elastic PE results for a $4 \mathrm{~km}$ deep water layer with a Munk deep water sound speed profile lies on top of an elastic halfspace A $10 \mathrm{~Hz}$ seismic source is placed $2 \mathrm{~km}$ below the ocean bottom interface. The solid red curve shows transmission loss at $z_{r}=1300 \mathrm{~m}$, which is the axis of the SOFAR channel. The solid black curve is the average transmission loss for 10 realizations of Gaussian ocean bottom roughness, which occurs for the first $25 \mathrm{~km}$ of propagation. The shaded region represents one standard deviation of transmission loss results. Until about $40 \mathrm{~km}$, the results are similar. However as range increases, additional acoustic energy scatters into the SOFAR channel and begins to dominate the propagation. At $120 \mathrm{~km}$ the average of the transmission loss from the rough bottoms is more than $20 \mathrm{~dB}$ for both compressional and shearing seismic source.
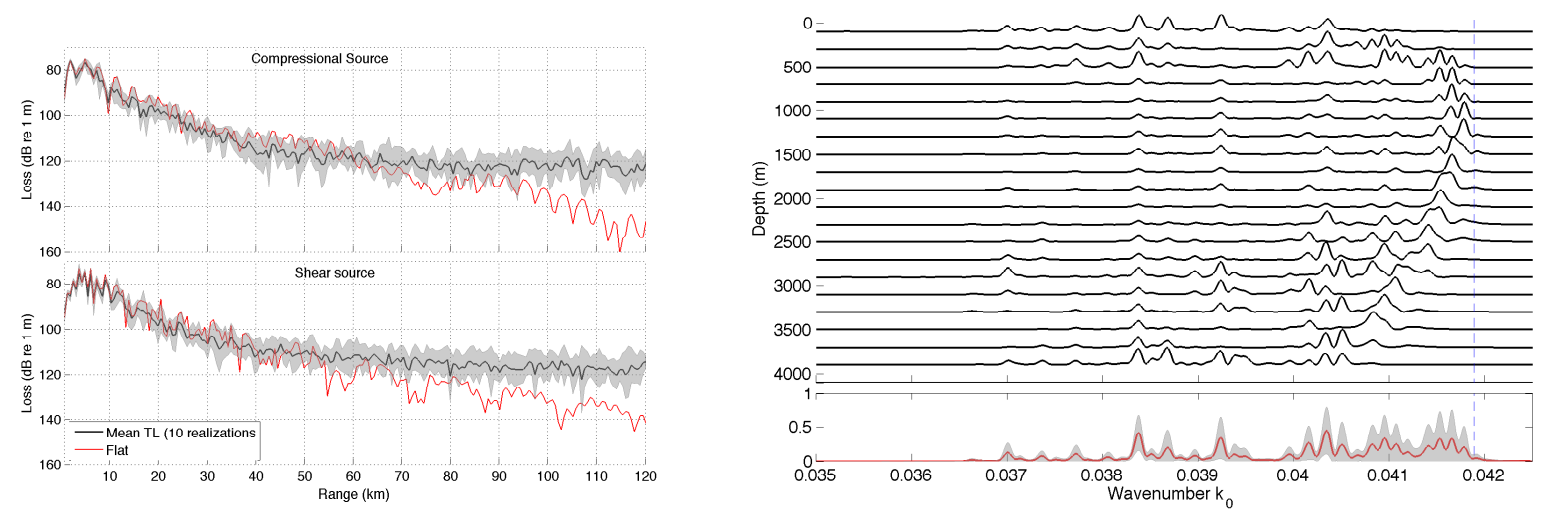

Figure 1: Elastic parabolic equation results for $4 \mathrm{~km}$ deep water layer over an elastic half space with a $10 \mathrm{~Hz}$ source is at $z_{s}=6 \mathrm{~km}$. (Left) Red curves show transmission loss at $z_{r}=1300 \mathrm{~m}$ when the ocean bottom is flat. Black solid curves shows show average transmission loss at $z_{r}=1300 \mathrm{~m}$ for 10 realizations where the first $25 \mathrm{~km}$ of the ocean bottom is rough. Shaded region shows standard deviation of results from these realizations and confirms that roughness near the seismic source leads to reduced transmission loss associated with T-waves. (Right) Wavenumber spectra for single rough bottom realization in the same environment for every $200 \mathrm{~m}$ depth show evidence of propagating modes in the water column. Depth average (red curve) and standard deviation (shaded region) of wavenumber spectrum are shown at bottom of panel. 
The right panel of Figure 1 shows wavenumber spectra at $120 \mathrm{~km}$ range and several depths for one realization in the environment described above. The arrival pattern, specifically the peaks near the blue dashed line (indicating average ocean sound speed) to the right of the figure at $1250 \mathrm{~m}$, confirms the presence of low-order modes propagating in the SOFAR channel. Many peaks appear at lower wavenumber values (to the left of the figure) indicating that high order modes remain in the received signal. These peaks are particularly strong near the ocean bottom and their associated signals would arrive much later than those observed near the SOFAR channel axis.
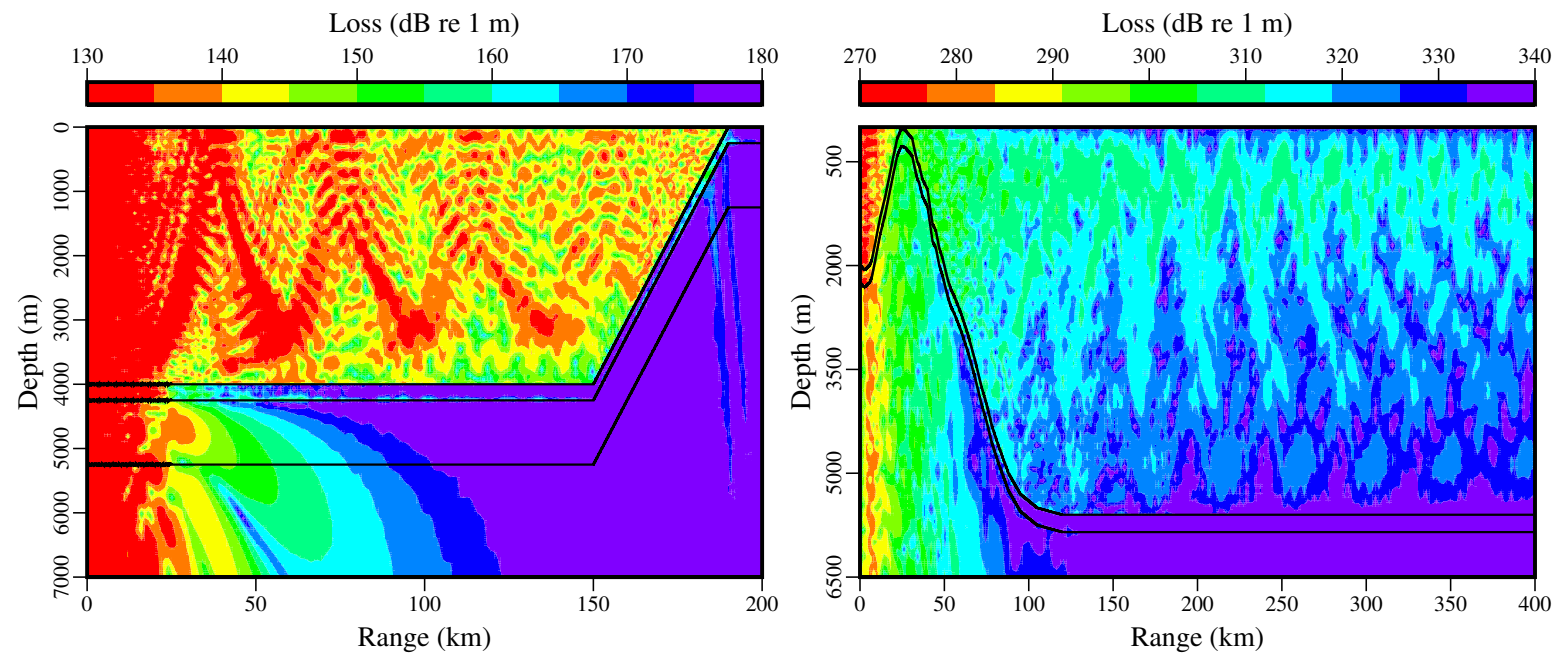

Figure 2: (Left) Elastic parabolic equation solution for a $10 \mathrm{~km}$ deep $10 \mathrm{~Hz}$ shear source showing abyssal T-wave energy traveling in the SOFAR channel and upslope onto land via a beach. The solution includes $10 \mathrm{~km}$ of zero water depth beginning at $r=190 \mathrm{~km}$. Three-layer ocean bottom consists of elastic sediment layer, a transitional elastic layer, and a hard elastic layer. Normally distributed roughness occurs along the first $25 \mathrm{~km}$ of the ocean-bottom interface. There is an apparent interface wave between elastic layers (approx. $4250 \mathrm{~m}$ depth) and evidence of mode cutoff as the acoustic energy moves upslope. (Right) A $5 \mathrm{~Hz}$ shear self-starter is $20 \mathrm{~km}$ below the ocean bottom in an environment featuring a seamount. A T-wave is generated by the downward slope of the seamount and travels to a range of $400 \mathrm{~km}$ in the SOFAR channel of a Munk deep ocean sound-speed profile.

The left panel of Fig. 2 shows an elastic PE solution for a $10 \mathrm{~km}$ deep $10 \mathrm{~Hz}$ seismic source in a $4 \mathrm{~km}$ deep ocean environment with a Munk deep water sound speed profile. Ocean bottom roughness occurs on a layered elastic bottom for the first $25 \mathrm{~km}$ of acoustic propagation. The oceanic $T$-wave is clearly propagating and has multiple turning points before the environment begins to slope upwards as for a continental shelf. This solution illustrates the ability of the elastic PE to generate abyssal $T$-waves, and apparent interface waves, which can be seen along the interface between two elastic layers at $4250 \mathrm{~m}$ depth. Propagation of the $T$-wave as purely elastic energy can be seen $10 \mathrm{~km}$ past where the water layer disappears.

The right panel of Fig. 2 shows a solution for a $5 \mathrm{~Hz}$ seismic self-starter $20 \mathrm{~km}$ below the ocean bottom to represent a very deep earthquake-type source. The ocean layer is $2.5 \mathrm{~km}$ deep at $r=0$ and lies over a layered elastic ocean bottom. The top of the seamount intersects the ocean surface, assuring that acoustic energy to the right of the seamount has been converted from elastic waves in the seamount via downslope conversion. Substantial acoustic energy is transferred to the oceanic $T$-wave, which 
propagates near the SOFAR channel axis (approx. $700 \mathrm{~m}$ deep in this example) to a range of $400 \mathrm{~km}$. This solution could be extended to much longer ranges.
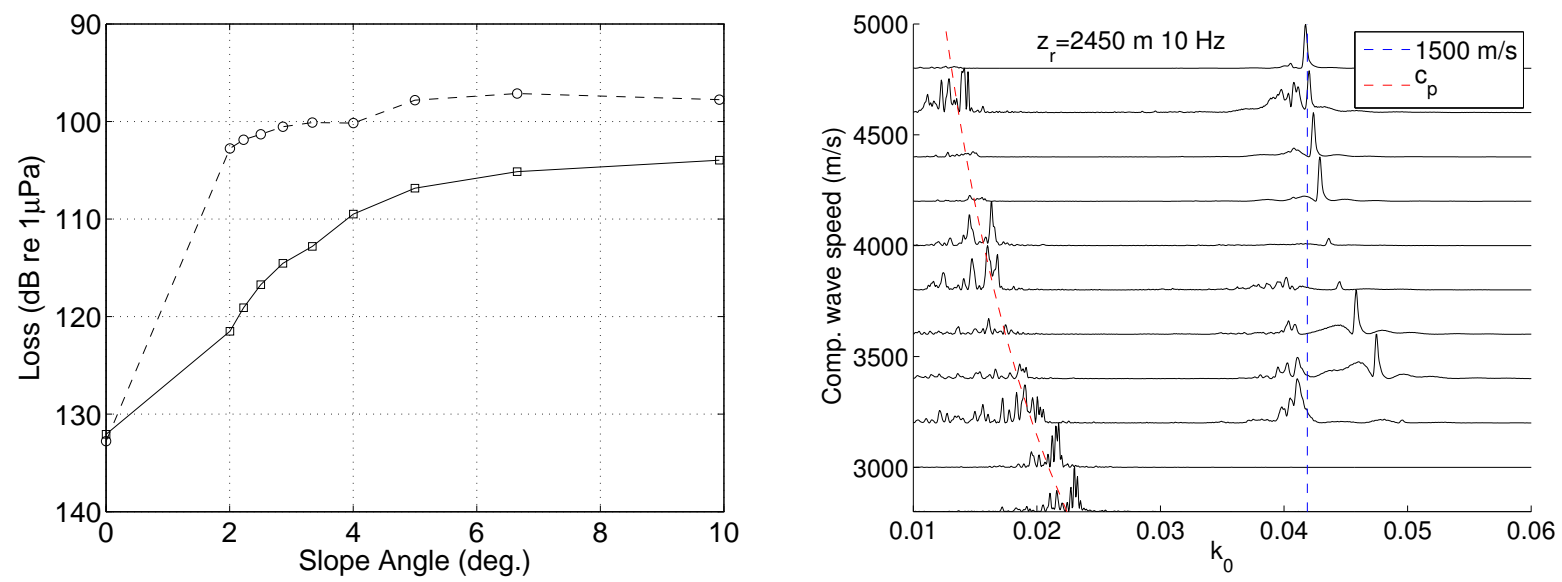

Figure 3: (Left) Effects of changing slope angle on depth averaged transmission loss at $150 \mathrm{~km}$ range for a $5 \mathrm{~Hz}$ compressional (solid line with circles) and shear (dashed line with squares) seismic source at $10 \mathrm{~km}$ depth. The angle of $0^{\circ}$ represents a $4 \mathrm{~km}$ deep flat environment In both cases the transmission loss values show a trend that decreases with increasing slope angle. (Right) Wavenumber spectra at $z_{r}=2450 \mathrm{~m}$ for varying $c_{p}$ in a $2500 \mathrm{~m}$ deep ocean environment with a one-layered elastic bottom $c_{s}=0.5 c_{p}$. A $10 \mathrm{~Hz}$ acoustic source is located at $z_{s}=500 \mathrm{~m}$. A $2000 \mathrm{~m}$ tall seamount lies between the source and the receiver, which is $100 \mathrm{~km}$ away. Large amplitude of propagating modes (near blue dashes) corresponds to smaller amplitude of elastic modes (near red dashes) and varies with elastic parameters. Scholte wave speed increases with increasing $c_{p}$.

The left panel of Fig. 3 illustrates the effect of slope angle on depth-averaged transmission loss, which serves as a proxy for $T$-wave amplitude. The environment utilizes a Munk deep water sound speed profile and slopes linearly from an initial ocean depth of $0.5 \mathrm{~km}$ to $4 \mathrm{~km}$ deep over a range governed by the slope angle. Transmission loss results were obtained at a range of $150 \mathrm{~km}$. Both types of seismic sources show that $T$-wave amplitudes increases with slope angle. In addition, the transmission loss results appear to be approaching a limiting value as the angle increases.

Elastic material parameters impact the long range acoustic wave field near the ocean bottom. For the right panel of Fig. 3 a $2500 \mathrm{~m}$ deep ocean with a Munk deep water profile is used. A $10 \mathrm{~Hz}$ acoustic source is placed at $500 \mathrm{~m}$ depth and the signal propagates $100 \mathrm{~km}$. A $2000 \mathrm{~m}$ tall seamount is located between the source and receiver at a range of $15 \mathrm{~km}$. When the acoustic energy interacts with the elastic material in the seamount, both oceanic $T$-waves and Scholte interface waves are generated. The figure shows wavenumber spectra at $z_{r}=2450 \mathrm{~m}$ for increasing values of $c_{p}$ in the elastic medium. The shear wave speed $c_{s}=0.5 c_{p}$ for all curves. As $c_{p}$ increases the amplitude of the Scholte wave peaks to the right of the ocean wave speed (blue dashes) varies. For very high values of the elastic parameters the Scholte wave peak begins to dominate propagating elastic modes. It is apparent that the amount of energy in the Scholte wave affects the amount of elastic energy that propagates in elastic body modes (peaks near red dashes). 


\section{IMPACT/APPLICATIONS}

- Improved modeling capabilities of elastic parabolic equation methods for underwater acoustic problems where elastic properties of the bottom cannot be ignored. Specific cases include the generation and propagation of oceanic $T$-waves by seismic sources which are relevant for geophysical study or test ban treaty monitoring.

- Oceanic $T$-waves and interface waves are potential explanations for "deep seafloor arrivals" and the reception of acoustic signals in what may be otherwise considered a quiet ocean environment for monitoring.

- Advances in modeling acoustic propagation in elastic layers has potential application in ice covered environments where an elastic layer lies on top of the water column.

\section{RELATED PROJECTS}

This research relates to the separately funded work of Robert Odom (Applied Physics Laboratory, University of Washington) regarding the two-way coupled mode code. It also relates to parabolic equation development by Jon M. Collis (Colorado School of Mines).

\section{REFERENCES}

[1] Brian D. Dushaw, Bruce M. Howe, James A. Mercer, Robert C. Spindel, and the ATOC Group. Multimegameter-range acoustic data obtained by bottom-mounted hydrophone arrays for measurement of ocean temperature. IEEE J. Ocean. Eng., 24(2):202-214, April 1999.

[2] Ralph A. Stephen, S. Thompson Bolmer, Matthew A. Dzieciuch, Peter F. Worcester, Rex K. Andrew, Linda J. Buck, James A. Mercer, John A. Colosi, and Bruce M. Howe. Deep seafloor arrivals: An unexplained set of arrivals in long-range ocean acoustic propagation. J. Acoust. Soc. Am., 126(2):599-606, August 2009. doi: 10.1121/1.3158826.

[3] Wayne Jerzak, William L. Siegmann, and Michael D. Collins. Modeling Rayleigh and Stoneley waves and other interface and boundary effects with the parabolic equation. J. Acoust. Soc. Am., 117(6):3497-3503, June 2005. doi: 10.1121/1.1893245.

[4] Donald A. Outing, William L. Siegmann, Michael D. Collins, and Evan K. Westwood. Generalization of the rotated parabolic equation to variable slopes. J. Acoust. Soc. Am., 120(6):3534-3538, December 2006. doi: 10.1121/1.2372590.

[5] Elizabeth T. Küsel, William L. Siegmann, and Michael D. Collins. A single-scattering correction for large contrasts in elastic layers. J. Acoust. Soc. Am., 121(2):808-813, February 2007. doi: $10.1121 / 1.2404627$.

[6] Jon M. Collis, William L. Siegmann, Finn B. Jensen, Mario Zampolli, Elizabeth T Küsel, and Michael D. Collins. Parabolic equation solution of seismo-acoustics problems involving variations in bathymetry and sediment thickness. J. Acoust. Soc. Am., 123(1):51-55, January 2007. doi: 10.1121/1.2799932. 
[7] Michael D. Collins. The stabilized self-starter. J. Acoust. Soc. Am., 106(4):1724-1726, October 1999.

[8] Scott D. Frank, Robert I. Odom, and Jon M. Collis. Elastic parabolic equation solutions for elastic bottom underwater acoustic problems using seismic sources. J. Acoust. Soc. Am., 133(3):1358-1367, 2013.

[9] Emile A. Okal. The generation of T-waves by earthquakes. In Renata Dmowska, editor, Advances in Geophysics, volume 49, pages 1 - 65. Elsevier, 2008.

[10] Minkyu Park, Robert I. Odom, and Darin J. Soukup. Modal scattering: a key to understanding oceanic T-waves. Geo. Res. Let., 28(17):3401-3404, 2001.

[11] Scott D. Frank, Jon M. Collis, and Robert I. Odom. Elastic parabolic equation solutions for oceanic $T$-wave generation and propagation from deep seismic sources. J. Acoust. Soc. Am., (submitted).

[12] Guust Nolet and LeRoy M. Dorman. Waveform analysis of Scholte modes in ocean sediment layers. Geophys. J. Int, 125:385-396, 1996.

[13] Rhett Butler and Cinna Lomnitz. Coupled seismoacoustic modes on the seafloor. Geo. Res. Let., 29(10), 2002. doi: 10.1029/2002GL014722.

[14] Scott D. Frank, Jon M. Collis, and Robert I. Odom. Generation and propagation of oceanic $T$-waves using elastic parabolic equation solutions (A). J. Acoust. Soc. Am., 134(5):4112, 2013.

[15] Scott D. Frank, Jon M. Collis, and Robert I. Odom. Wavenumber analysis of interface wave characteristics using elastic parabolic equation solutions(A). J. Acoust. Soc. Am., 135(4):2168, 2014.

[16] Jon M. Collis, Scott D. Frank, Adam M. Metzler, and Robert I. Odom. Seismic sources in seismo-acoustic propagation models (A). J. Acoust. Soc. Am., 134(5):4208, 2013.

\section{PUBLICATIONS}

- Submitted to refereed journal (JASA): [11]

- Presentations: [14], [15],[16] 